\title{
TEMPORAL AND SPATIAL ANALYSIS OF URBAN HEAT ISLAND USING LANDSAT SATELLITE DATA: TWO INDIAN CASE STUDIES
}

\author{
K. Dutta ${ }^{1}$, D. Basu ${ }^{2}$, S. Agrawal ${ }^{3}$ \\ ${ }^{1}$ MNNIT Allahabad, GIS Cell, Allahabad, Uttar Pradesh 211004, India - rgi1604@mnnit.ac.in \\ ${ }^{2}$ MNNIT Allahabad, Dept. Of Civil Engineering, Allahabad, Uttar Pradesh 211004, India - basud@mnnit.ac.in \\ ${ }^{3}$ MNNIT Allahabad, GIS Cell, Allahabad, Uttar Pradesh 211004, India - sonam@mnnit.ac.in
}

Commission V, WG V/7

KEY WORDS: Urban heat island, Satellite image, NDBI, SAVI, Change detection, Spatiotemporal pattern

\begin{abstract}
:
Urban environment is examined through time series Landsat TM (Thematic Mapper) and OLI/TIRS (Operational Land Imager \& Thermal Infrared Sensor) sensor images. A continuous surface of Land Surface Temperature (LST) can be extracted from Landsat thermal bands. Similarly different band combinations and ratios will give spatial pattern of land cover categories. Among the se, building and vegetation indices are used to characterize the spatiotemporal pattern of elevated temperature zones in cities. This excess heat concentration creates thermal hotspots which are known as Urban Heat Islands (UHI). Parameters of land cover are then related to LST to detect the influence of urbanization on intensity and extent of heat islands, by pixel based quantitative analysis. This paper focuses on two megacities of India and their surrounding districts for identifying the critical UHI areas. The purpose of this paper is to create a database for reconstruction in old cities and planning of new smart cities. Results suggest that urban sprawl and substitution of rural areas with impervious surface plays significant role in microclimate, causing formation of new thermal hotspots. The analysis of urban thermal environment and its dynamics is to provide a scientific basis for future strategy building.
\end{abstract}

\section{INTRODUCTION}

Population of $21^{\text {st }}$ century is getting increasingly urban focused. Rapid urbanization is expected to continue globally, particularly in Asia and Africa through 2030 (UN Habitat, 2007). Urbanization has been depicted as massive and unplanned landscape change (Kotze et al., 2011). India, has witnessed significant conversion of rural land to urban areas, especially around megacities. It raises frequent challenges to urban sustainability. In urban areas due to land cover changes and rising energy consumption, relatively higher land surface and air temperature can be observed (usually higher at night) than rural areas at the same point of time. This phenomenon is referred to as UHI (Oke, 1995). The trapping of heat in impervious surfaces and reduction in vegetated land causes the elevated temperatures for city regions. This intensification of heat in local climate causes certain health disorders (Kolokotsa et al., 2009, Deosthali, 2000). To improve quality of life in cities along with social and economic indicators, health issues are to be added on. Poor planning of cities in terms of congestion in residential areas, lack of greenery, building heights affecting wind circulation, high building density and conversion of wetlands into impervious surface leads to the thermal hotspots generation. There is a need for planning and design communities to step up to resolve this problem. Urban planning and designing is location based operation. Hence, including UHI locations in infrastructure development activity and design principles will help to create energy efficient cities.

Historically UHI study was limited due to lack of data, which was observed from a few sparsely spaced weather stations (Auer, 1977). Availability of satellite imageries in thermal infrared region leads to the continuous accessibility for LST data (Weng, 2009). The remotely sensed data has high resolution, repetitive coverage and capability of consistent measurement of earth surface conditions (Owen et al., 1998).
Remotely sensed time series images also detect the change in certain indices to assess the causes behind the spatial distribution of thermal hotspots. Such studies have been carried out in different cities over the world (Price, 1979, Yuan et al., 2005, Liu et al., 2011) and many of them show the influence of urbanization on local atmosphere (Nichol, 2005, Singh et al., 2016).

Urban environment parameters can be mapped along with UHI for better understanding of urban landscape. The impervious surface area can be mapped by Normalized Difference Building Index (NDBI) calculation which is usually positively related to temperature pattern of a region. The standardized difference of Near Infrared (NIR) and Mid Infrared (MIR) bands results in extraction of built up pixels (Zha et al., 2003). Using the NDBI thematic map built up or impervious surface area can be extracted by thresholding method (Lu et al., 2013). Among other indices the biophysical parameter of vegetation is widely used for validating UHI patterns. Vegetation indices are calculated based on the difference in red and infrared canopy reflectance in ratio form. In case of urbanized areas, the impervious surface and soil conditions have considerable alterations on indices value and partial canopy spectra. To adjust this soil brightness variation Soil Adjusted Vegetation Index (SAVI) (Huete, 1988) is computed. SAVI can work in areas where vegetation cover is as low as $15 \%$.

In India UHI study has been conducted only in few cities (Mohan et al., 2012); but the effects of spreading urban land on surrounding districts haven't been looked into through UHI, building and vegetation indices. These areas have experienced rapid changes over last few decades. Hence the study will aid to smart city planning in satellite towns. This will also help in rezoning of older cities. There are two objectives of this research work. The first objective is to perform quantitative 
analysis of spatiotemporal patterns of UHI hotspots. The second objective is to analyze the correlation between LST and indices in order to evaluate the influence of anthropogenic activities for improved decision making in future.

\section{STUDY AREA}

\subsection{NCR Region}

The first study area is the National Capital Region (NCR) which is located between $28^{\circ} 05^{\prime} \mathrm{N}$ to $29^{\circ} 13^{\prime} \mathrm{N}$ latitude and $76^{\circ} 40^{\prime} \mathrm{E}$ to $78^{\circ} 13^{\prime} \mathrm{E}$ longitude, as shown in Figure 1. This includes the National Capital Territory of Delhi (NCT) and the districts of Meerut, Ghaziabad, Gautam Buddha Nagar, Faridabad and Gurgaon. As per 2011 census, the urbanization level in this region is $62.6 \%$. The land use has undergone a severe change for last few years as urban agglomeration is taking place. This area comes under humid subtropical climate.

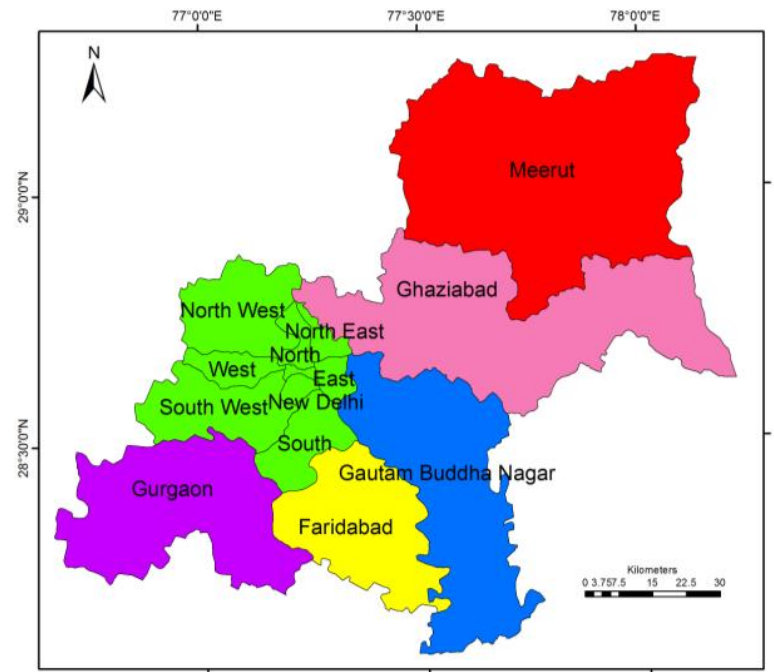

Figure 1. Study area 1

\subsection{South-East West Bengal Region}

Unlike the inland location of $1^{\text {st }}$ study area, the $2^{\text {nd }}$ region has a coastal location. It includes the districts of Kolkata, Howrah, North 24 Parganas and South 24 Parganas of West Bengal

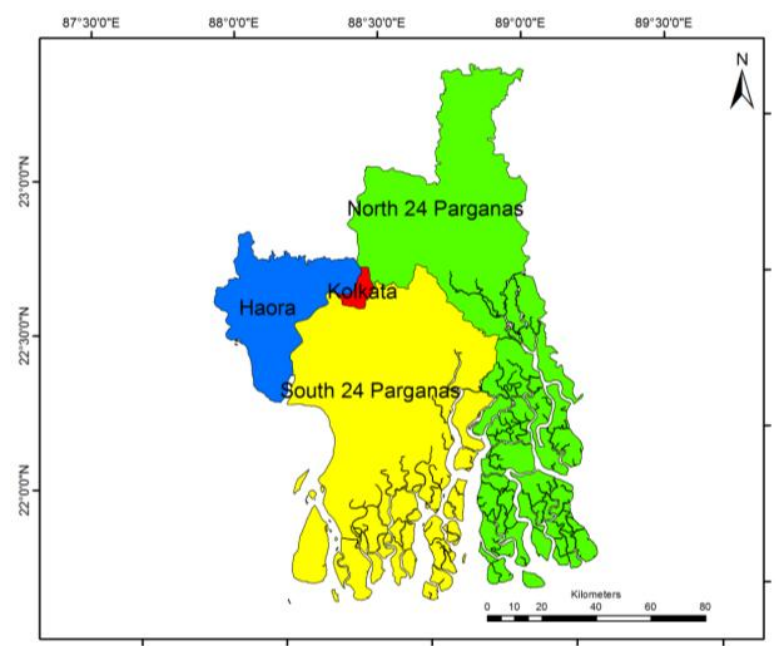

Figure 2. Study area 2 extending from $21^{\circ} 33^{\prime} \mathrm{N}$ to $23^{\circ} 15^{\prime} \mathrm{N}$ latitude and $87^{\circ} 51^{\prime} \mathrm{E}$ to $89^{\circ} 06^{\prime} \mathrm{E}$ longitude, as shown in Figure 2. Other than the Kolkata city region this area also contains the North 24 Parganas which is the highest populated district of India. The whole region is experiencing urban sprawl in recent years. The area comes under tropical wet and dry climatic zone.

\section{DATA CHARACTERISTICS}

Landsat TM and OLI/TIRS sensor data is used for analyzing LST and land use patterns. The thermal band for TM sensor has a resolution of $120 \mathrm{~m}$ and the rest of the bands are of $30 \mathrm{~m}$ resolution. For OLI_TIRS the multispectral bands are of $30 \mathrm{~m}$ and thermal bands are of $100 \mathrm{~m}$ spatial resolution. Temporal study is executed with satellite imageries of 3 years with interval of around a decade. Detail of imageries used in the study is given in Table 1 . Secondary data of district maps are used among other auxiliary data.

\begin{tabular}{|c|c|c|}
\hline Sensor & Date & Path-Row \\
\hline TM & 01.03 .1998 & $146-40,147-40$ \\
\hline TM & 27.02 .2009 & $146-40,146-41,147-40$ \\
\hline OLI/TIRS & 08.03 .2018 & $146-40,147-40$ \\
\hline TM & 09.03 .1998 & $138-44,138-45$ \\
\hline TM & 07.03 .2009 & $138-44,138-45$ \\
\hline OLI/TIRS & 12.02 .2018 & $138-44,138-45$ \\
\hline
\end{tabular}

Table 1. Imageries used in the study

\section{METHODOLOGY}

The overall methodology is shown in figure 3. Following processing techniques are applied on the Landsat images to fulfill the objectives.

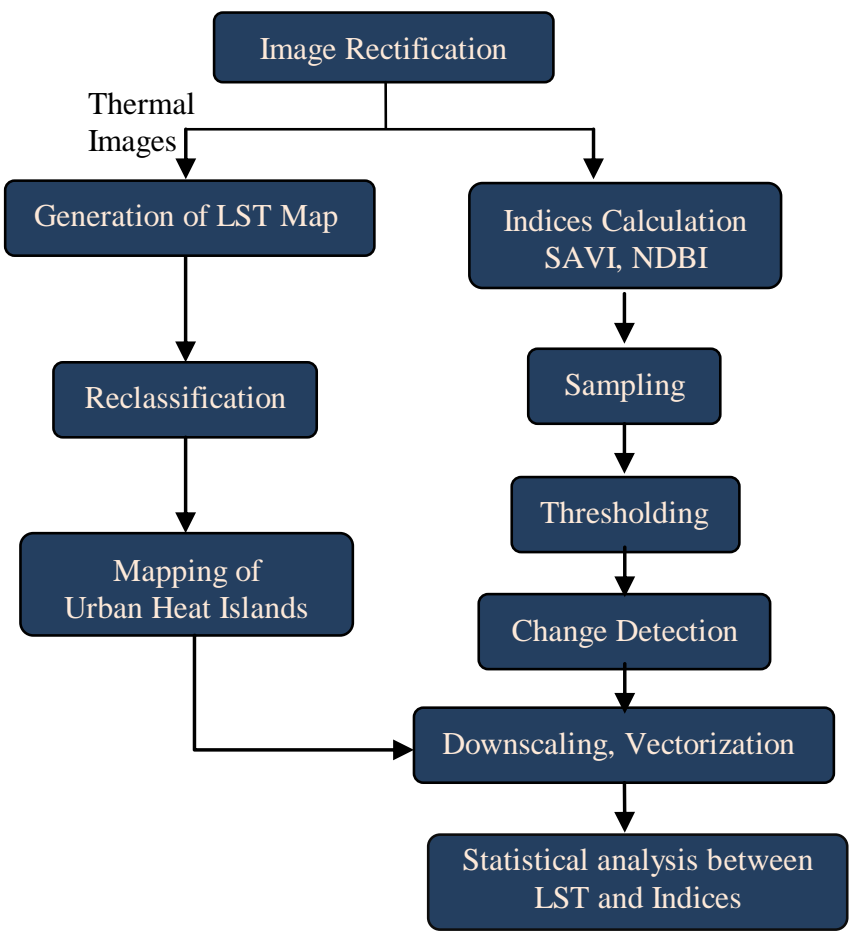

Figure 3. Flowchart of Methodology 


\subsection{Image Rectification}

4.1.1 Radiation Correction: It includes the conversion of pixel DN (Digital Number) to at-sensor radiance, subtraction of atmospheric illumination effects and sensor calibration. While comparing multiple imageries it is better to use spectral radiance rather than using $\mathrm{DN}$ values directly. The conversion is carried out with the following formula (Landsat Project Science Office, 2002)

$$
\begin{gathered}
\mathrm{L}_{\lambda}=\left[\left(\operatorname{LMax}_{\lambda}-\operatorname{LMin}_{\lambda}\right) /(\mathrm{QCalMax}-\mathrm{QCalMin})\right] *(\mathrm{QCal}- \\
\mathrm{QCalMin})+\operatorname{LMin}_{\lambda}
\end{gathered}
$$

where

$\mathrm{L}_{\lambda}=$ spectral radiance at the sensor's aperture in $\mathrm{W} /\left(\mathrm{m}^{2} \mathrm{sr}\right.$ $\mu \mathrm{m})$

$\operatorname{LMax}_{\lambda}=$ spectral radiance that is scaled to QCalMax in $\mathrm{W} /\left(\mathrm{m}^{2} \mathrm{sr} \mu \mathrm{m}\right)$

$\operatorname{LMin}_{\lambda}=$ spectral radiance that is scaled to QCalMin in $\mathrm{W} /\left(\mathrm{m}^{2} \mathrm{sr} \mu \mathrm{m}\right)$

$\mathrm{QCal}=$ quantized calibrated pixel value in digital number

QCalMax = maximum quantized calibrated pixel value in digital number

QCalMin $=$ minimum quantized calibrated pixel value in digital number

It has been proved that radiation correction improves the accuracy of LST and other index calculation (Song et al., 2001).

4.1.2 Mosaicing and Stacking: The multiple corrected images covering the study area are then stitched together. The different bands, excluding blue (because blue band has maximum scattering) and thermal bands are then stacked together to generate the colour images for respective study areas.

\subsection{Image Processing}

4.2.1 LST Generation: The spectral radiance converted from pixel DN values is then used to compute brightness temperature (i.e. blackbody temperature) under the assumption of unit emissivity and using pre-launch calibration constants (Landsat Project Science Office, 2002).

where

$$
\mathrm{T}_{\mathrm{B}}=\mathrm{K}_{2} / \ln \left(1+\left(\mathrm{K}_{1} / \mathrm{L}_{\lambda}\right)\right)
$$

$\mathrm{T}_{\mathrm{B}}=$ effective temperature in Kelvin

$\mathrm{K}_{1}$ and $\mathrm{K}_{2}=$ pre-launch calibration constants

For TM, $\mathrm{K}_{1}=607.76 \& \mathrm{~K}_{2}=1260.56$

For OLI/TIRS, $\mathrm{K}_{1}=774.8853 \& \mathrm{~K}_{2}=1321.0789$

Finally the Kelvin temperature is converted to land surface temperature in Celsius $\left(\mathrm{T}_{\mathrm{S}}\right)$ as,

$$
\mathrm{T}_{\mathrm{S}}=\mathrm{T}_{\mathrm{B}}-273
$$

\subsubsection{SAVI Computation: It is calculated as,} SAVI $=[(\mathrm{NIR}-\mathrm{Red})(1+\mathrm{l})] /(\mathrm{NIR}+\mathrm{Red}+\mathrm{l})$ where

$$
1=\text { correction factor ranging from } 0 \text { to } 1
$$

As per standard methods in this case the value of 1 is taken as 0.5 (Xu, 2007).
4.2.3 NDBI Computation: This index is generated with the following equation,

$$
\mathrm{NDBI}=(\mathrm{MIR}-\mathrm{NIR}) /(\mathrm{MIR}+\mathrm{NIR})
$$

\subsection{Thresholding and Change Detection}

Representative pixels of different land cover categories are selected based on stacked colored images and maps. The DN values are used to determine a range which decides threshold for separating built up and vegetation. The decadal change in built up and vegetated lands are then computed as percentage area.

\subsection{Correlation Analysis by Downscaling and} Vectorization

LST, SAVI and NDBI images are downscaled from $30 \mathrm{~m}$ resolution to $120 \mathrm{~m}$ and $100 \mathrm{~m}$ for TM and OLI sensor data respectively. Correlation between LST and indices is the maximum at $120 \mathrm{~m}$ resolution which is believed to be the operational scale of for TM sensor (Weng, 2004). Nearest neighbor resampling is used afterwards. The raster images are then vectorized to point files. Perason's Product Moment Correlation analysis between pixels of LST map and indices maps are then performed.

\section{RESULTS}

\subsection{Results of NCR Region}

The LST maps of this region have been generated for 1998 , 2009 and 2018 as shown in Figure 4, Figure 5 and Figure 6. The expanding heat island is clearly visible over decadal change analysis. In 1998, temperature hotspots can be observed in small patches over southwest Delhi, Delhi-GurgaonFaridabad border, eastern fringe of Delhi. After two decades Meerut and Ghaziabad cities can be seen as growing heat islands in Figure 6. In the study area, Delhi is the megacity which can be considered as the major centre of heat island.

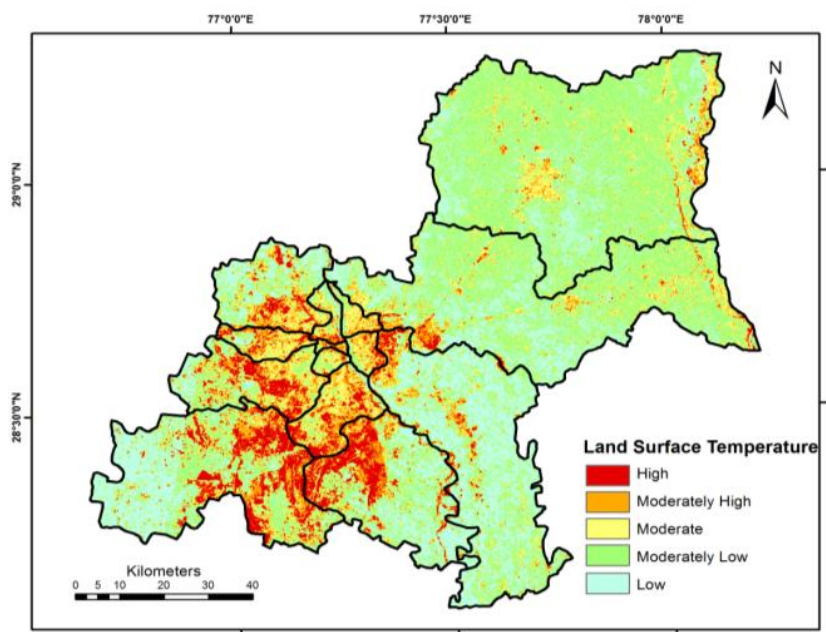

Figure 4. LST Map of NCR for 1998 


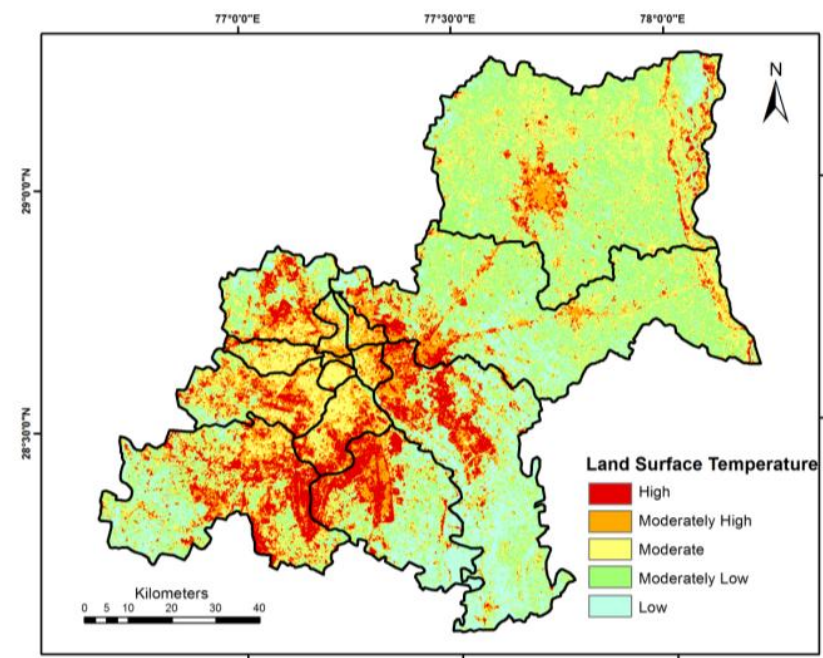

Figure 5. LST Map of NCR for 2009

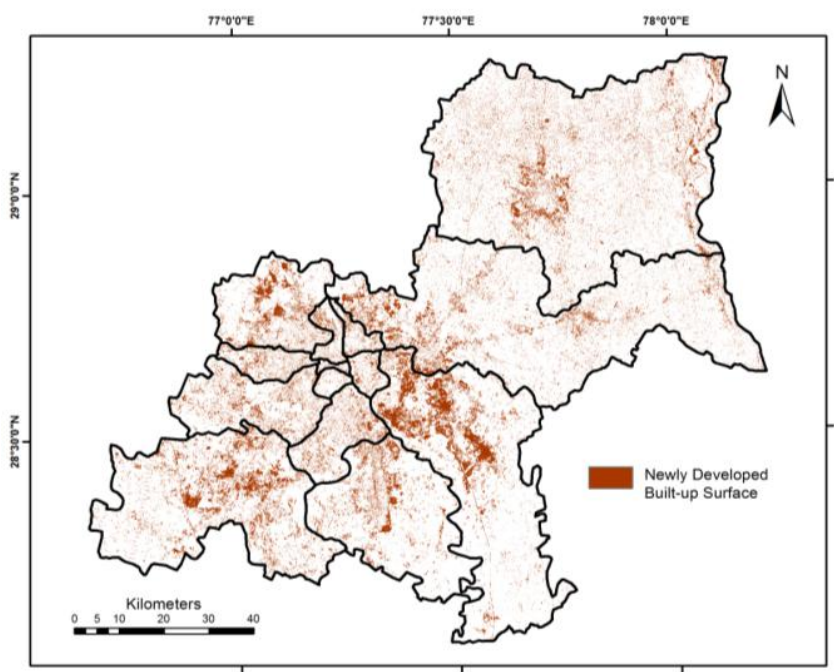

Figure 7. Newly Developed Built-up Surface in NCR from 1998 to 2009

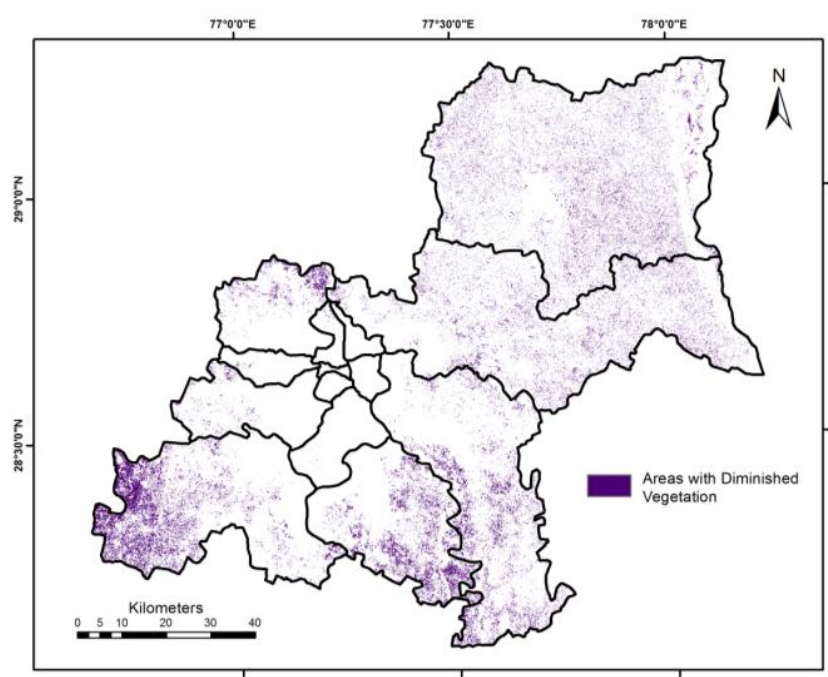

Figure 9. Areas with Diminished Vegetation in NCR from 1998 to 2009

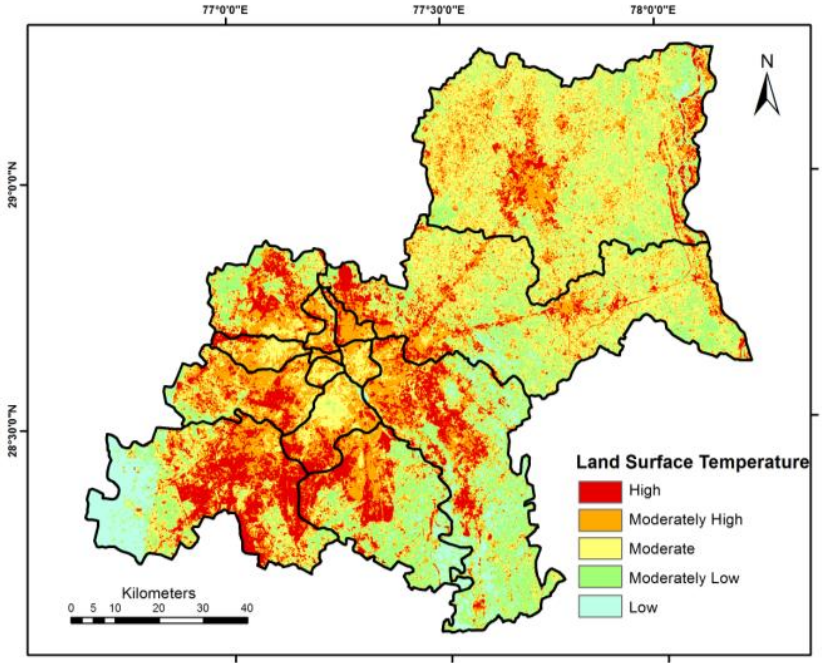

Figure 6. LST Map of NCR for 2018

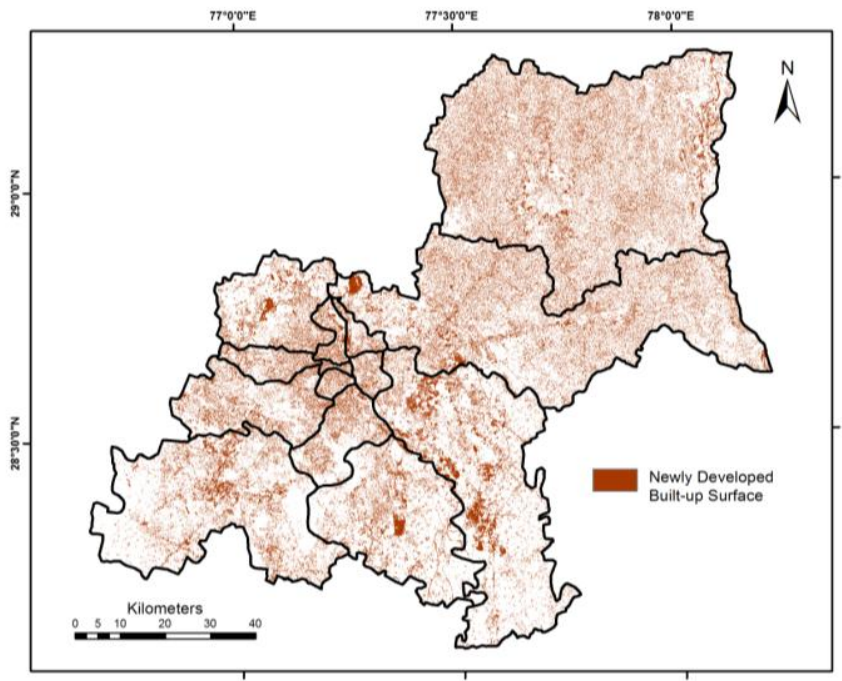

Figure 8. Newly Developed Built-up Surface in NCR from 2009 to 2018

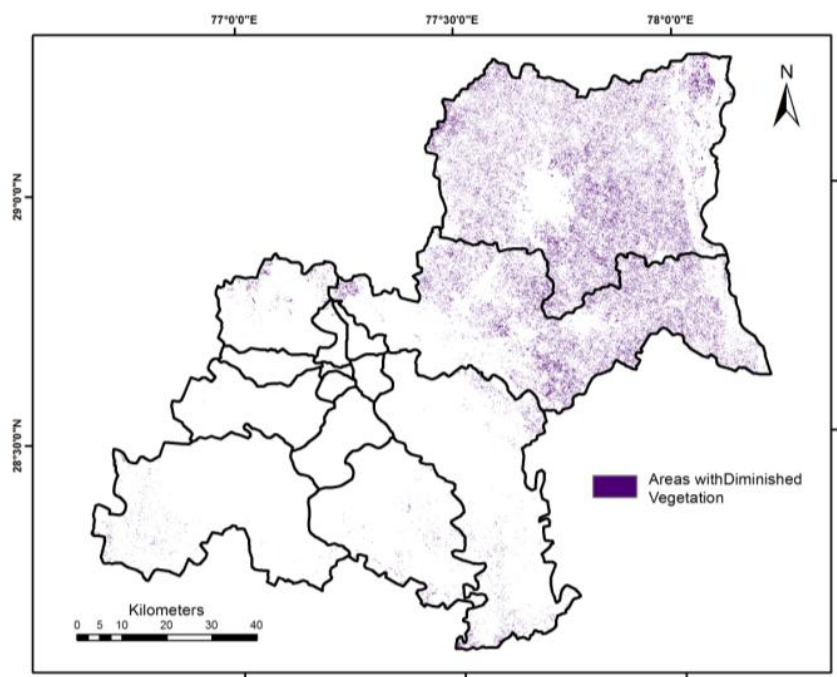

Figure 10. Areas with Diminished Vegetation in NCR from 2009 to 2018 
Throughout the study period, this heat island distinctly visible. It has been spread and intensified in surrounding districts specially of east Gurgaon, north Faridabad and north central Gautam Budhha Nagar.

The NDBI image is prepared for the years 1998, 2009 and 2018. The difference in impervious surface cover is determined by raster subtraction. Figure 7 and Figure 8 show the newly developed built-up area between 1998 and 2009, 2009 and 2018 respectively. The newly developed built up surface between two decades clearly match with the newly generated temperature hotspots for every decade. High positive correlation between NDBI and LST also shows the contribution of impervious surface on urban heat island formation. Similarly for SAVI three images are generated for the three years. Difference images are then prepared which represent areas of deforestation. These are shown in Figure 9 and Figure 10. The correlation of temperature with built up and vegetation is shown in Table 2.

\begin{tabular}{|l|l|l|l|l|}
\hline Variables & $\mathbf{1 9 9 8}$ & $\mathbf{2 0 0 9}$ & $\mathbf{2 0 1 8}$ & $\begin{array}{l}\text { Significance } \\
\text { level }\end{array}$ \\
\hline $\begin{array}{l}\text { Temperature } \\
\text { and Built up }\end{array}$ & 0.71 & 0.62 & 0.76 & $99 \%$ \\
\hline $\begin{array}{l}\text { Temperature } \\
\text { and Vegetation }\end{array}$ & -0.66 & -0.58 & -0.69 & $99 \%$ \\
\hline
\end{tabular}

Table 2. Correlation coefficient $\left(\mathrm{R}^{2}\right)$ between temperature and indices for NCR

After analyzing the changes of land cover for surrounding districts of Delhi, it is observed that Gautam Budhha Nagar experienced maximum change in percentage area of impervious surface. $24.86 \%$ area got covered by newly developed built up from 1988 (12.16\% of the whole area) to 2018 (37.02\% of the whole area). It explains the rapidly growing number of hotspots in this commercial area. On the other hand Faridabad marks the least growth in terms of built up surface, from $23.91 \%$ to $42.35 \%$ over 20 years. Vegetation loss for the two decades is maximum in Meerut with $3.69 \%$ surface area becoming non vegetated (in 2018) from vegetation (in 1988). Along with this, urbanization in and around Meerut city with increase of $18.61 \%$ impervious area caused the remarkable generation and expansion of heat islands.

\begin{tabular}{|l|l|l|l|}
\hline Land Cover Type & $\mathbf{1 9 9 8}$ & $\mathbf{2 0 0 9}$ & $\mathbf{2 0 1 8}$ \\
\hline Built up Surface & 21.4 & 25.99 & 43.23 \\
\hline Vegetation & 11.0 & 8.12 & 7.40 \\
\hline
\end{tabular}

Table 3. Area of land cover category (values in percentage) from 1998 to 2009

Rapid changes can be observed in Delhi also. Impervious surface covered $22.47 \%$ more area of the total in the later decade. Vegetated area is continuously decreasing. Though the rate of vegetation decrease slowed down. In the $1^{\text {st }}$ decade $2.09 \%$ area observed vegetation loss compared to $0.05 \%$ decrease in the $2^{\text {nd }}$ decade.

The changes in both vegetation and impervious surface are more distinct in the later decade, between 2009-2018, as shown in Table 3. The increase in built up area is $17.24 \%$ of the later decade is much higher than $4.59 \%$ areal increase of the first decade. This rate of urbanization necessitates extensive planning to accommodate playing fields, parks and other public places. Adaptive designing and landscaping might help the critical heat island region containing large population.

\subsection{Results of South East West Bengal Region}

The three LST maps are prepared for the second study region as well and are shown in Figure 11, Figure 12 and Figure 13. In this study area heat island is distinctly observed over Kolkata city. For 1998 the sandy areas in southern parts show relatively higher temperature than rest of the places. This elevated temperature is not caused by urbanization. A relatively smaller heat island can be seen growing in Kolkata city from Figure 11. It is to be noticed that East of Kolkata the Rajarhat - New Town area of North 24 Parganas is coming under lowest temperature category. After two decades this area clearly shows hotspots development, as in Figure 13. The heat island of Kolkata can be seen expanding into parts of east and north Howrah, south east North 24 Parganas and north of South 24 Parganas. Another major heat island has intensified over Barasat (North 24 Parganas) for the recent years.

NDBI images are generated for the three years of 1998, 2009 and 2018. Raster subtraction between 2009-1998 and 20182009 resulted in the built-up surface change images. They are shown in Figure 14 and Figure 15. Among the surrounding districts of Kolkata, Howrah shows maximum development of built up surface ( $22.98 \%$ area in two decades). The vegetation decrease is shown by difference images of SAVI. Two images are prepared for representing changes in two decades. Figure 16 shows the areas with vegetation decrease from 1998 to 2009 and Figure 17 represents vegetation loss from 2009 to 2018. The currently growing heat islands in North 24 Parganas are mostly over residential or commercial built up land and so needs fast mitigation. From Figure 17 it can be seen that, between 2009 and 2018 the vegetation loss in Howrah district is drastic. This proves the rapid rate of urbanization at the expense of vegetation. The LST maps also show a continuous increase in surface temperature. Analyzing the changes it can be seen that the later decade experienced severe land cover alteration.

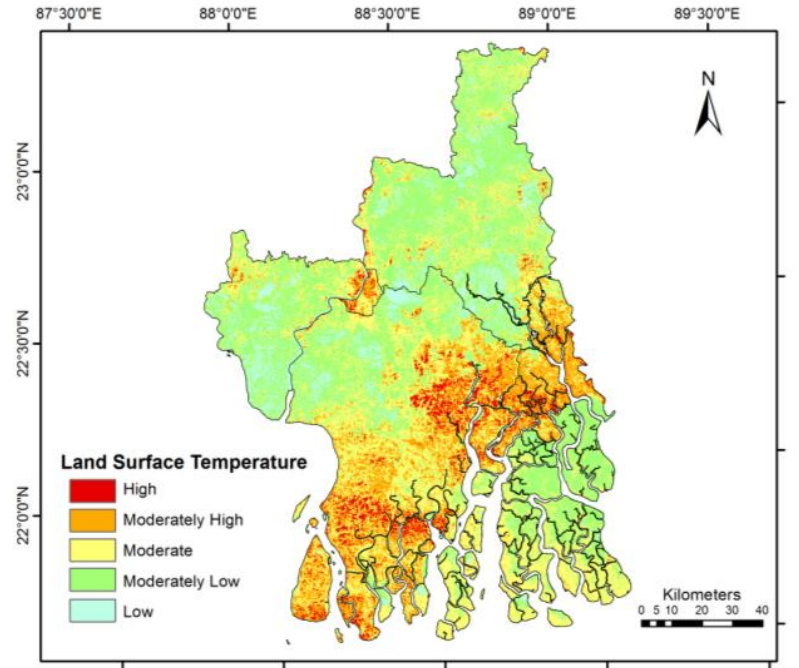

Figure 11: LST Map of South-east West Bengal for 1998 


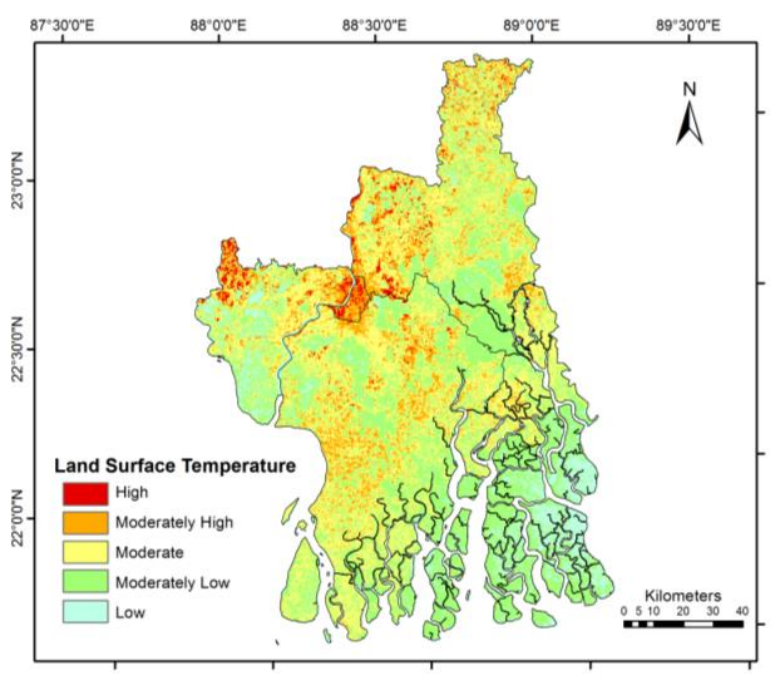

Figure 12. LST Map of South-east West Bengal for 2009

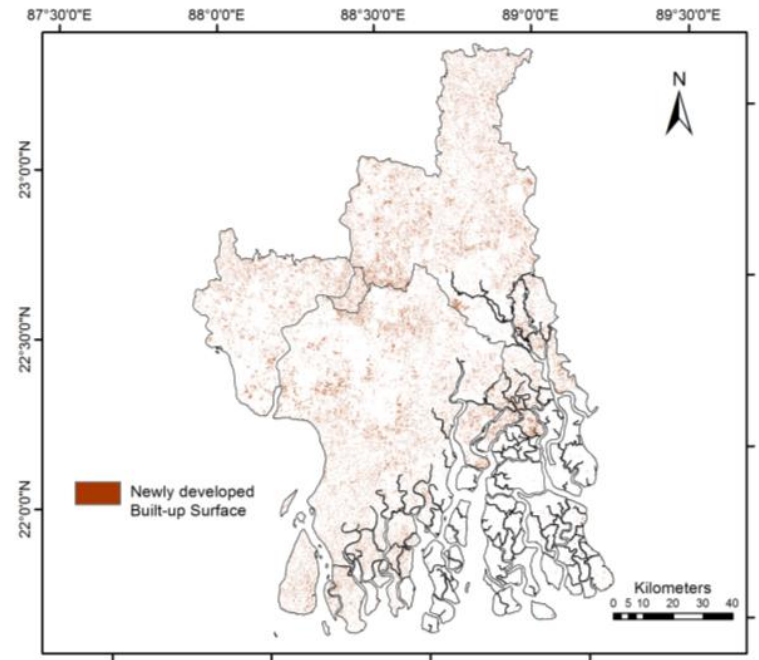

Figure 14. Newly Developed Built-up Surface in South-east West Bengal from 1998 to 2009

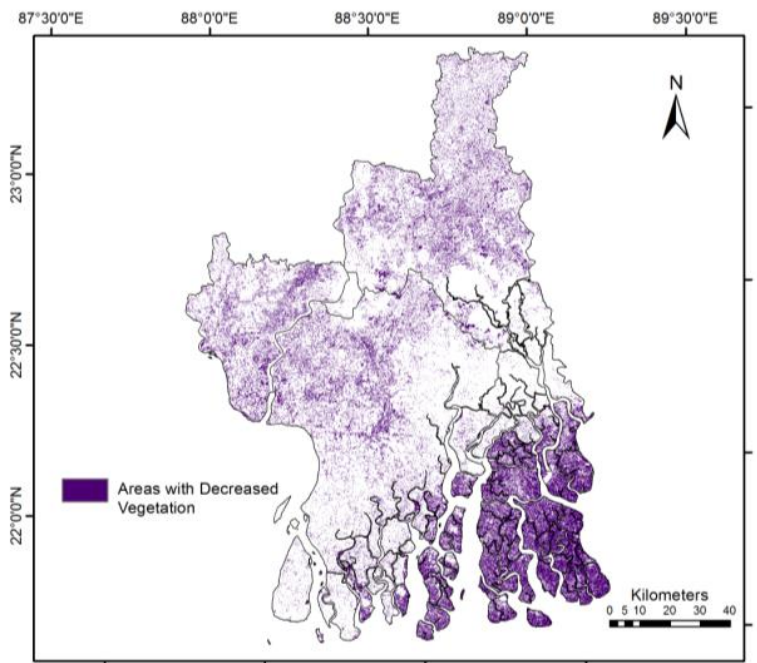

Figure 16. Areas with Diminished Vegetation in South-east West Bengal from 1998 to 2009

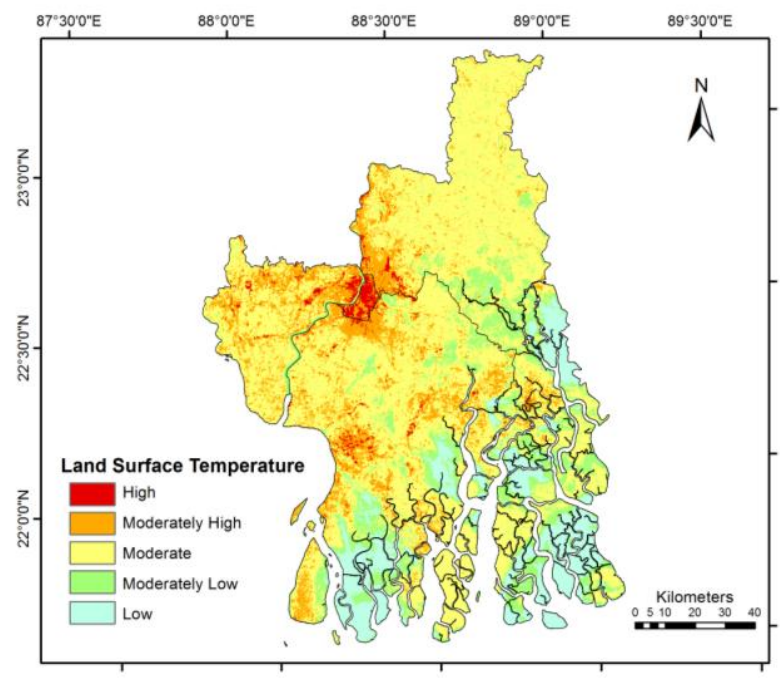

Figure 13. LST Map of South-east West Bengal for 2018

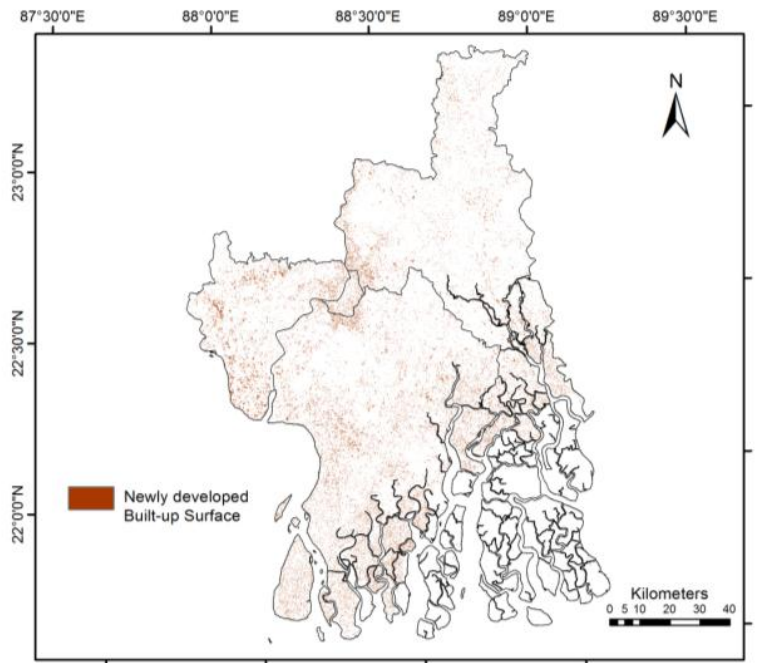

Figure 15. Newly Developed Built-up Surface in South-east West Bengal from 2009 to 2018

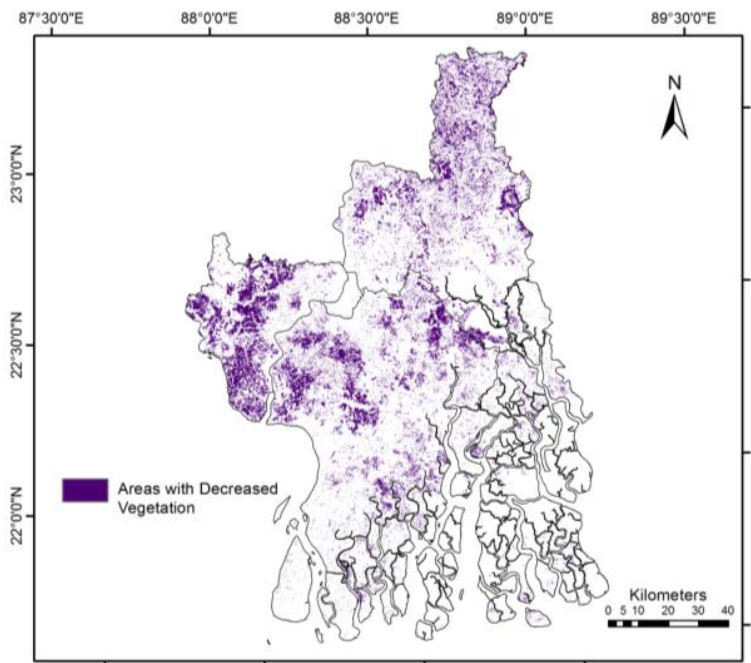

Figure 17. Areas with Diminished Vegetation in South-east West Bengal from 2009 to 2018 
Correlation coefficient values between NDBI-LST and SAVILST are given in Table 5. The correlation analysis shows positive relation between NDBI and LST for the region. SAVI and LST is negative or nearly zero. Though the correlation values' significance level is $99 \%$, it is clearly observable that for NCR region the correlation coefficients showed better results. For West Bengal region there might be other factors involved affecting LST pattern.

\begin{tabular}{|l|c|c|c|l|}
\hline Variables & $\mathbf{1 9 9 8}$ & $\mathbf{2 0 0 9}$ & $\mathbf{2 0 1 8}$ & $\begin{array}{l}\text { Significance } \\
\text { level }\end{array}$ \\
\hline $\begin{array}{l}\text { Temperature \& } \\
\text { Built up }\end{array}$ & 0.66 & 0.76 & 0.33 & $99 \%$ \\
\hline $\begin{array}{l}\text { Temperature \& } \\
\text { Vegetation }\end{array}$ & -0.28 & -0.21 & 0.08 & $99 \%$ \\
\hline
\end{tabular}

Table 5. Correlation coefficient $\left(\mathrm{R}^{2}\right)$ between temperature and indices for south-east West Bengal

Table 6 showing percentage area under different land cover categories, displays increasing built-up area. The vegetation cover shows decrease in the first decade by $9.3 \%$ area of the whole; but it has increased for $4.1 \%$ of the total area in the next decade.

\begin{tabular}{|l|l|l|l|}
\hline $\begin{array}{l}\text { Land Cover } \\
\text { Type }\end{array}$ & $\mathbf{1 9 9 8}$ & $\mathbf{2 0 0 9}$ & $\mathbf{2 0 1 8}$ \\
\hline Built up Surface & 22.9 & 23.75 & 28.06 \\
\hline Vegetation & 36.2 & 26.9 & 31 \\
\hline
\end{tabular}

Table 6. Area of land cover categories (values in percentage of the total area) from 1998 to 2018

The Kolkata city needs urgent attention from developers to mitigate the heat island effects. It has caused increasing power consumption and affected health by extreme heat conditions on both day and night. It will be a great challenge to reconstruct old city areas; but future planning projects must include UHI related environmental indicators in the framework of policy making. The negative correlation between LST and vegetation shows that increasing green areas will help to diminish UHI intensity.

\section{CONCLUSION}

The study has shown distinct development of UHI in the megacities and surrounding areas over two decades. The LST maps show excess heat trapping in city centres while temperature decreases towards the rural areas. The spatiotemporal pattern of heat islands is mapped and by decadal change analysis first objective is completed. The study provides much needed insight into functioning of large city regions. Also it is noticeable from the maps that, in recent time period districts bordering megacities have undergone rapid changes. In NCR the built-up surface covered $21.4 \%$ of total area in 1998 , which has increased to $43.23 \%$ by 2018 . On the other hand vegetated surface decreased from $11 \%$ of the total area to $7.40 \%$ by 2018 . Similar results are found for south-east West Bengal region. There the built-up has grown from 22.9\% to $28.06 \%$, from 1998 to 2018 . Vegetation cover has reduced from $36.2 \%$ to $31 \%$ over the two decades. Newly developing thermal hotspots are clearly detected in these areas of changes. The knowledge of urban thermal landscape must be a part of designing policies. Otherwise it will create inhospitable environment for residents of urban fringe areas. In case of NCR thermal hotspots have developed rapidly in urban fringes. These are commercial and residential areas experiencing large population bloom in recent decades. Expanding built up surface at the expense of vegetation and rising thermal hotspots, proves the increasing pressure of urbanization on local climate. The second objective is fulfilled by relating urban ecological parameters to surface heat. For the second study region the heat island seem to concentrate in patches over Kolkata. The formation of heat island is probably at an earlier stage than NCR. Though similar to NCR a few hotspots are seen to develop on the recently built residential and commercial zones. The critical hotspot areas need public spaces like playing fields, parks, green roofs as UHI mitigation measures. The projection of demographics shows the population pressure to be exerted upon cities and urban fringes. Many smart cities will be developing in the coming years. If not dealt with caution unplanned sprawling will lead to same conditions now observed over centre of megacities. Landscape ecologists should consider building heights, interspatial distances between them, percent green area, floor area ratio for an energy efficient planning. It is time for taking a transdisciplinary approach to monitor UHIs with GIS and remote sensing techniques in this new urban world.

\section{REFERENCES}

Auer, A.H., 1978. Correlation of Land Use and Cover with Meteorological Anomalies. J. Appl. Meteorol., 17, pp. 636643.

Deosthali, V., 2000. Impact of rapid urban growth on heat and moisture islands in Pune City, India. Atmospheric Environment, 34, pp. 2745-2754.

Huete, A. R., 1988. A soil-adjusted vegetation index (SAVI). Remote Sens. Environ. 1988, 25, 295-309.

Kolokotsa, D., Psomas, A., and Karapidakis, E., 2009. Urban heat island in southern Europe: The case study of Hania, Crete. Sol. Energy, 83, pp. 1871-1883.

Kotze, J., Venn, S., Niemelä, J., and Spence, J., 2011. Effects of Urbanization on the Ecology and Evolution of Arthropods, Urban Ecology, pp. 159-166.

Landsat Project Science Office., 2002. Landsat 7 Science data user's handbook. Goddard Space Flight Center, NASA: Washington, DC

Lu, D., Li, G., Kuang, W., and Moran, E., 2013. Methods to extract impervious surface areas from satellite images. International Journal of Digital Earth, 7(2), pp. 93-112.

Liu, L., and Zhang, Y., 2011. Urban heat island analysis using the Landsat TM data and ASTER Data: A case study in Hong Kong. Remote Sens., 3, 1535-1552.

Mohan,M., Kikegawa,Y., Gurjar,B.R., Bhati,S., Kandya,A., and Ogawa,K., 2012. Urban Heat Island Assessment for a 
Tropical Urban Airshed in India. Atmospheric and Climate Sciences, 2, pp. 127-138.

Nichol, J., 2005. Remote Sensing of Urban Heat Islands by Day and Night. Photogrammetric Engineering \& Remote Sensing, 71(5), pp. 613-621.

Oke, T.R., 1995. The Heat Island of the Urban Boundary Layer:Characteristics, Causes and Effects. World Climate in cities, pp. 81-107.

Owen, T. W., Carlson, T. N., and Gillies, R. R., 1998.An assessment of satellite remotely-sensed land cover parameters in quantitatively describing the climatic effect of urbanization. Int. J. Remote Sens, 19, pp. 1663-1681.

Price, J. C., 1979. Assessment of the urban heat island effect through the use of satellite data. Monthly Weather Review, 107, pp. 1554-1557.

Singh, J., Vittal, H., Karmakar, S., Ghosh, S., and Niyogi, D., 2016. Urbanization causes nonstationarity in Indian Summer Monsoon Rainfall extremes. Geophys. Res. Lett., 43(11), pp. 269-277.

Song, C., Woodcok, C. E., Seto, K. C., Lenney, M. P., and Macomber, S. A., 2001. Classification and Change Detection Using Landsat TM Data: When and How to Correct Atmospheric Effects? Remote Sensing of Environment, 75, pp. 230-244.

UN-Habitat, 2007. Twenty First Session of the Governing Council, Nairobi, Kenya.

Weng, Q., Lu, D., and Schubring, J., 2004. Estimation of land surface temperature - vegetation abundance relationship for urban heat island studies. Remote Sensing of Environment, 89 (4), pp. 467-483.

Weng, Q., 2009. Thermal infrared remote sensing for urban climate and environmental studies : Methods, applications, and trends. ISPRS J. Photogramm. Remote Sens., 64, pp. 335344.

Xu, H., 2007. Extraction of Urban Built-up Land Features from Landsat Imagery Using a Thematic oriented Index Combination Technique. Photogrammetric Engineering \& Remote Sensing, 73(12), pp. 1381-1391.

Yuan, F., Sawaya, K.E., Loeffelholz, B.C., and Bauer, M.E., 2005. Land cover classification and change analysis of the Twin Cities (Minnesota) metropolitan area by multitemporal Landsat remote sensing. Remote Sens. Environ., 98, pp. 317328 .

Zha, Y., Gao, J., and Ni, S., 2001. Use of normalized difference built-up index in automatically mapping urban areas from TM imagery. Int.J.Remote Sensing, 24(3), pp. 583-594.
Zhao, X., Huang, J., Ye, H., Wang, K., and Qiu, Q., 2010. Spatiotemporal changes of the urban heat island of a coastal city in the context of urbanisation. International Journal of Sustainable Development \& World Ecology, 17 (4), pp. 311316 . 